\title{
One Suitable Type Adaptation Operational Characteristics Of Universal Lathe to the New Needs
}

\author{
Branko Pejović $^{1 *}$, Aleksandar Todić ${ }^{1}$, Nemanja Vasić ${ }^{1}$, Bojan Tatić ${ }^{2}$ \\ ${ }^{1}$ Univerzitet u Prištini, Fakultet tehničkih nauka u Kosovskoj Mitrovici, Kneza Miloša br.7, 38220 Kosovska Mitrovica, \\ Srbija \\ ${ }^{2}$ Univerzitet u Kragujevcu, Fakultet za mašinstvo i građevinarstvo u Kraljevu, Dositejeva 19, 36000 Kraljevo, Srbija
}

In this paper is determined dependence on the motive power of the cutting speed for exploitative area efficiency on tool machine life and cross section chips for a universal machine tool for processing by scraping. These dependences were used to determine the main features of the optimal and maximal motive power machine. On the basis of this, analysed of the increase in motive power machine for characteristical cases in order to adapt the exploitation characteristics on the new requirements for the purpose of improve productivity.

Using the previous analysis, it was determined the best solution from the aspect a rational design of the machine, while simultaneously provided the utilization of the main features on the basis of increase in rpm using increased tool life. In order to better presentation of problems, analysed in the appropriate diagrams PV and VD.

On the characteristic example of manufacturing practices, at the end of this paper, is given the overview of improvements exploitation characteristics of a universal lathe appropriate calculations from the aspect of adjustment the characteristics on the new requirements, with the expectation that the reconstruction of the machine will be the lowest.

Keywords: machine tools, a universal lathe, the exploitative characteristics, exploitation analysis, the increase in power and rpm of machines, tool life, cutting resistance, the prevailing torque, the optimal diameter of processing.

\section{INTRODUCTION}

For existing machine tools in operation it is possible to perform their modernization representing certain requirements which a machine for various reasons translate from one to the new, more constructionexploitation, condition, [1], [2], [3].

Groups of the most important goals in the modernization of machine tools were to increase: highspeed movement, installed power, level of automation, changing technological level and range of application. Modernization of machine tools also acknowledge to certain limitations of that are present in the analysis production program and capacity, [3], [4], [5], [7]. It should be emphasized that the problem of finding of favorable conditions of utilization of machine tools in the existing literature has not yet adequately treated, and if it is an important factor in increasing the productivity of machines, [5], [6], [8].

Conditions to be met by every machine tool would be: accuracy, productivity and efficiency. Equally important are the trends in the achievement of high speed in order to implement the tools high endurance, as well as increased resistance to cutting ie section filings, with the aim of increasing productivity. In relation to previously, there is a need for a greater operating force of machines, whereby it is important that it be determined according to the optimum mode of processing, [6], [7], [8], [9], [10], [11], [12], [13]. Choice motive power in machine tools is an important problem from the viewpoint of machine concepts and their of utilization in different modes of processing. At this in universal machine, as opposed to special machines, must be taken into consideration the whole area of applications and it will find the optimal mode of processing, as decisive for the calculation of capacity, given that this production tasks often change, [9], [10], [12].

\section{DETERMINATION OF MOTIVE POWER OF LATHE IN DIFFERENT PROCESSING REGIMES}

The main resistance of cutting to scraping process, can be expressed according to the elements of cross section chips $a[m], s[m / o],[5],[6],[7],[11]$, [14].

$$
F_{1}=C_{\kappa} \cdot a^{x_{1}} \cdot s^{y_{1}}[N]
$$

Factor $C_{k}\left[\mathrm{~N} / \mathrm{m}^{2}\right]$ is dependent on the material of the workpiece.

Previously adopted dimensions are not common but they are suitable for calculations that follow.

Cutting speed can be expressed in terms of the extended term: [2], [4], [12], [15]:

$$
V=\frac{C_{v}}{T^{m} \cdot a^{x} \cdot s^{y}} \cdot \zeta_{k} \cdot \zeta_{p} \cdot \zeta_{T}[\mathrm{~m} / \mathrm{s}]
$$

ie,

$$
V=\frac{C_{V}^{\prime}}{a^{x} \cdot s^{y}}
$$

where is a constant,

$$
C_{v}^{\prime}=\frac{C_{v} \cdot \zeta_{k} \cdot \zeta_{p} \cdot \zeta_{T}}{T^{m}}
$$


Factor $C_{v}\left[\frac{m}{s} \cdot m^{2}\right]$ depends on the material of the workpiece and the tool, whereas $\mathrm{T}$ [s] is tool life. Correctional coefficients that take into consideration glancing angle ie the material of the workpiece are $\zeta_{k}$ ie. $\zeta_{p}$

If the setpoint of the tool life $T$ different from the stability $T t$, which is usually $T t=60 \mathrm{~min}$, then the correction factor is:

$$
\zeta_{T}=\sqrt[Z]{\frac{T_{t}}{T}}
$$

where $Z$ experiment depends on the type of tools material and material of the workpiece, [1], [5], [6], [12], [16].

Note that the coefficients of workability $C_{v} x, y, m$ in equation (2) and (4), mostly determined in function by the stability $T t$.

By introducing slenderness coefficient of chips:

$$
g=\frac{a}{s}
$$

cutting speed, according to (3), being:

$$
V=\frac{C_{V}^{\prime}}{g^{x} \cdot s^{x+y}}
$$

being:

Required motion power at turnery processing

$$
P=\frac{F_{1} \cdot V}{\eta}[W]
$$

where is $\eta$ the level of efficiency machines.

The expression for the power $P_{A}$ in the area of full utilization, tool life and incomplete cross section chips may be obtained by (1) i (8), [2], [5], [6], [8], [12], [17]:

$$
P_{A}=\frac{C_{k} \cdot(g \cdot s)^{x_{1}} \cdot s^{y_{1}}}{\eta} \cdot V
$$

If express an shift from the expression (7):

$$
s=\left(\frac{C_{v}^{\prime}}{g^{x} \cdot V}\right)^{\frac{1}{x+y}}
$$

relation (9) becomes:

$$
P_{A}=\frac{C_{k}}{\eta} \cdot g^{x 1} \cdot\left(\frac{C_{v}^{\prime}}{g^{x} \cdot V}\right)^{\frac{x_{1}+y_{1}}{x \cdot y}} \cdot V
$$

After arranging, from here is obtained:

$$
P_{A}=\frac{C_{k}}{\eta} \cdot\left(C_{V}^{\prime}\right)^{\frac{x_{1}+y_{1}}{x+y}} \cdot g^{x_{1}-x \cdot \frac{x_{1}+y_{1}}{x+y}} \cdot V^{1-\frac{x_{1}+y_{1}}{x+y}}
$$

Power $P_{A}$ can be expressed of here as:

$$
P_{A}=\frac{k_{1} \cdot V^{Z_{A}}}{\eta}
$$

where $k_{1}=$ const, while the exponent $Z_{A}$ depends on factors $x_{1}, y_{1}, x, y$, and have a negative value $\left(z_{A}<0\right)$.
Expression (13) shows dependency on the power of the cutting speed if the tool life is constant, whereby if change to the cutting speed $V$ changes the value of the chip cross-section so that the ratio $g=a / s$ is constant. Increasing the cutting speed decreases power $P_{A}$, but at the same time reduces the chip cross-section with constant steadfestness $\left(C_{V}^{\prime}=\right.$ const $)$, according to hyperbolic dependence, Fig.1.

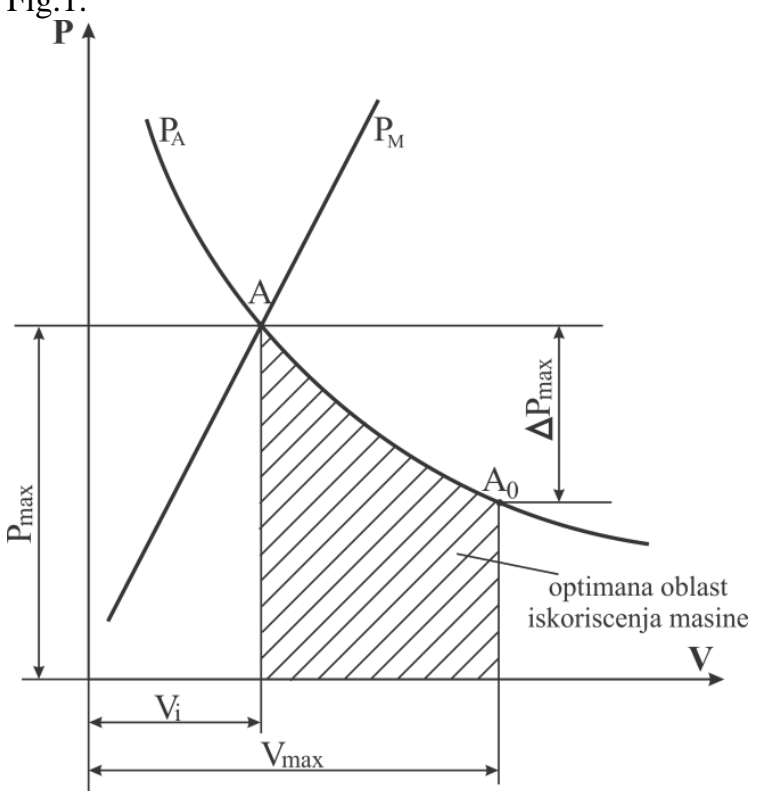

Fig. 1. Change of power at a constant tool life and a constant cross-section of chips

The expression for the power $P_{M}$ in area on full utilization cross-section of chips obtained by (8) i (1), [3], [5], [6], [7], [13], [18], [19]:

$$
P_{M}=\frac{C_{k} \cdot a_{\max }^{x_{1}} \cdot s_{\max }^{y_{1}} \cdot V}{\eta}
$$

where $a_{\text {max }}$ and $s_{\text {max }}$ are the maximum values of the cutting depth and the steps planned for that machine considering to its static stiffness and the material of the workpiece.

If we introduce the slenderness ratio to (6):

$$
g=\frac{a_{\max }}{s_{\max }}=\frac{a}{s}
$$

relation (13) becomes:

$$
P_{M}=\frac{C_{k}}{\eta} \cdot g^{x_{1}} \cdot s_{\max }^{x_{1}+y_{1}} \cdot V
$$

Of expression (15) can be seen that with increasing speed power increases too, while the chips cross-section expressed with a maximum step $s_{\max }$ and a constant ratio $\mathrm{a} / \mathrm{s}$ remain constant.

From the relation (15) follows a linear dependency:

$$
P_{M}=\frac{K_{2} \cdot V}{\eta}
$$

where $K_{2}=$ const, Fig.1. By increasing the chips crosssection grows coefficient $K_{2}$, and thus the slope of the rights in the system $(P, V)$.

From the previous it follows that the intersection of the functions of $P_{A}$ and $P_{M}$, point A will be the regime 
simultaneous utilization of the full cross-section of chips and full tool life, Fig.1.

Power at point $A$ is the maximum required motion power that can not be exceeded if not exceed the maximum cross-section of chips and maximum predicted tool life. This power corresponds to the optimal speed $V_{i}$, [1], [5], [6], [14], [20].

By eliminating the speed $V$ from equation (8), the expression (3)

$$
V_{1}=\frac{C_{v}^{\prime}}{a_{\max }^{x} \cdot s_{\max }^{y}}=\frac{C_{v}^{\prime}}{\left(g_{\max } \cdot s_{\max }\right)^{x} \cdot s_{\max }^{y}}
$$

it will be finally:

$$
P_{\max }=\frac{C_{k} \cdot C_{v}^{\prime}}{\eta} \cdot g_{\max }^{x_{1}-x} \cdot s_{\max }^{x_{1}+y_{1}-x-y}
$$

The torque while processing scraping:

$$
M_{\text {max }}=F_{1 \max } \cdot \frac{D}{2}
$$

linearly is changed with change processing diameter, at a constant maximum value of the main cutting resistance so that for $D_{\max }$ had a maximum value $M_{\max }^{\prime}>M_{\text {max }}$.

In order rational dimensioning of machine elements is introduced the term optimal diameter $D_{i}$ that can be processed in optimal regime, while the diameters $D>D_{i}$ being processed with a smaller cross-section of chips. The optimum diameter $D_{i}$ is diameter to be processed with the optimum $\operatorname{rpm} n_{i}$ ie optimal speed.

If we assume that the maximal diameter processed the same $\operatorname{rpm} n_{i}$ with speed $V_{\max }$ being (Fig. 2):

$$
D_{i}=\frac{V_{i}}{V_{\text {max }}} \cdot D_{\max }
$$

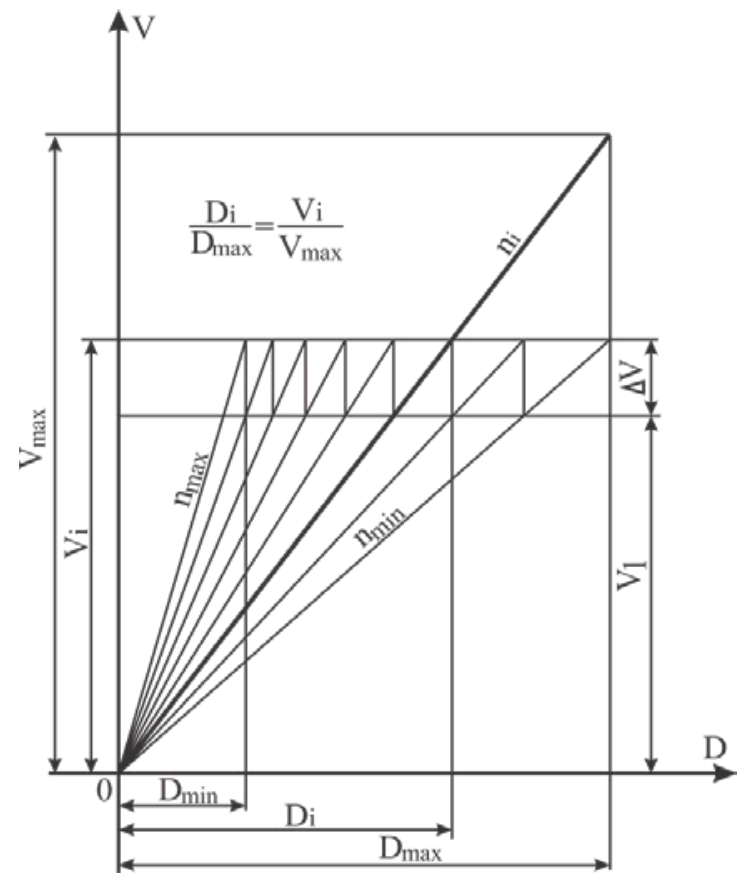

Fig. 2. Determination of the optimal diameter

The maximum speed $V_{\max }$ is that speed where the main features of the machine are within permissible limits ie. located in the areas permitted deviation from the optimal value. This area is shown in Fig. 1 hatched. When this, allowed decrease maximum power is $\Delta P_{\max },[4]$, [5], [6], [15], [22].

The values for the optimal diameter vary within the limits:

$$
D_{i}=(0,7 \div 0,8) \cdot D_{\max }
$$

while the torque that is taken in the design amounts [5], [6], [9], [15]:

$$
M_{\text {max }}=F_{1 \max } \cdot \frac{D_{i}}{2}
$$

\section{ANALYSIS OF THE POSSIBILITY OF INCREASING MOTIVE POWER IN LATHE}

If, in order to adapt to the new needs of machine tools, increase the driving power the lathe from the current values of $P_{\max }$ at $\bar{P}_{\max }$ will be deranged the balance in respect of efficiency cross-section chips and tool life. The horizontal line $\bar{P}_{\text {max }}$ intersects the lines $P_{A}$ and $P_{M}$, it being possible to extract the five characteristic cases (points 1, 2, 3, 4 and 5), according to Fig.3, and corresponding to the new optimal regimes, as shown in dashed lines in Fig. 4.

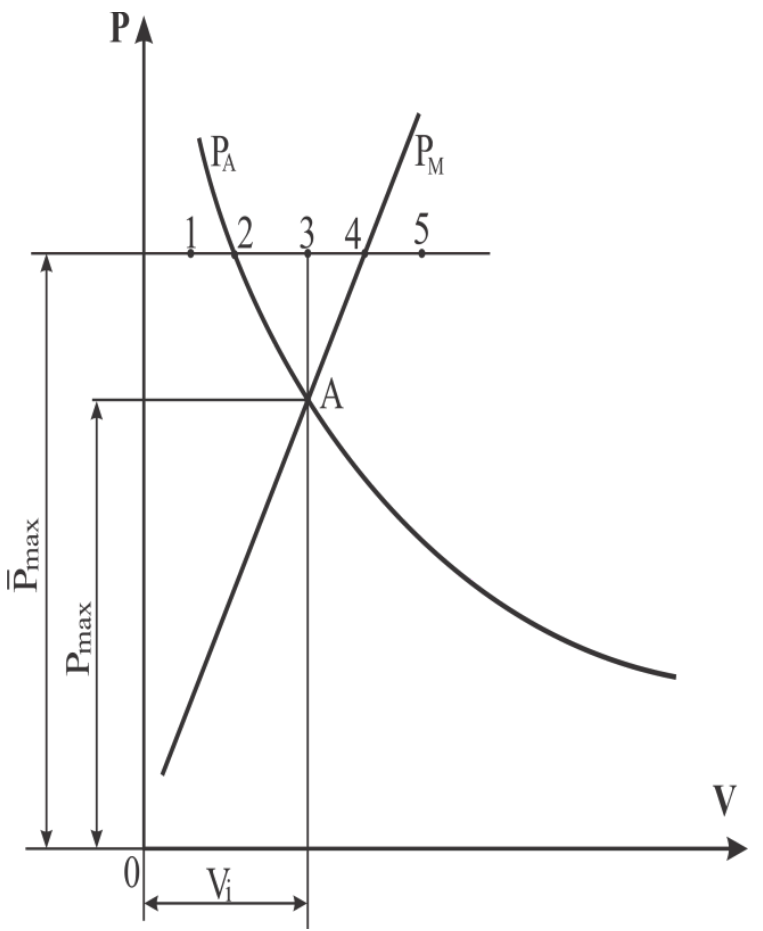

Fig. 3. Adapting machine tools to new needs by increasing the motive power

In point 1 , tool life and cross-section chips are not fully utilized. Rather straights $P_{M}$ and $P_{A}$ will be valid lines $P_{M 1}$ and $P_{A 1}$. In point 2 is fully utilized only tool life, while in point 4 is fully utilized only cross-section chips.

Straights $P_{M 1}, P_{M 2}$ and $P_{M 3}$ have a greater slope than the initial straight $P_{M}$, which, according to the relation (16), means an increase in cross-section chips in relation to the mode that corresponds to point $\mathrm{A}$. 


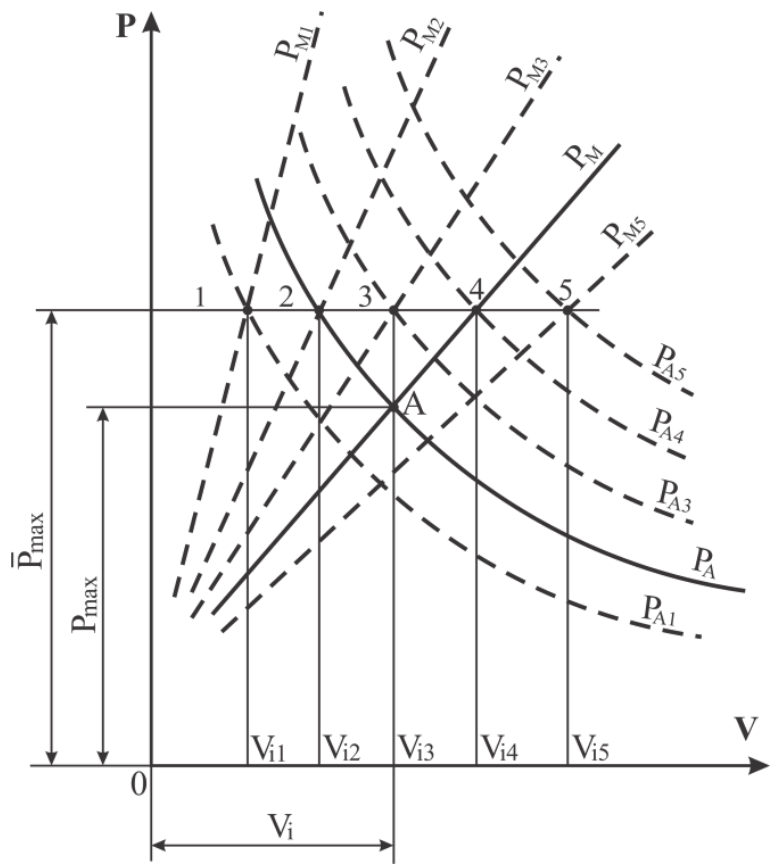

Fig. 4. Different cases match the machine to the new need with increasing the driving force

Obviously, cross-section of chips has at point A, $a_{\max } \cdot s_{\max }$, increased to the cross-sections: $a_{1 \text { max }} \cdot s_{1 \text { max }}, a_{2 \max } \cdot s_{2 \max }$ and $a_{3 \max } \cdot s_{3 \max }$, which represent exceeding of the maximum allowable capital cutting resistance $F_{1 \text { max }}$, and thus the resistance to penetration $F_{2 \max }$, for the points 1,2 and 3. This means that at a specific static stiffness of the machine, elastic deformation will be higher than the deformation of machinery before modernization. The required tool life in points 1,2 and 3 is less than the stability at point $A$, which means that the tool, in these points 1 and 2 , is fully utilized. Optimal speed, at points 1 and 2, is reduced compared to the speed $V_{i}$ at point A, while, in points 4 and 5 , is increased to the same relation.

In point 2 , the speed is reduced at a constant tool life $\left(T_{2}=T_{A}\right)$, this means that the cross section chips at this point shall increase, as has been said, considering the deformation of the machine, is not responding. In point 3 , the optimum speed is the same in relation to point A, while the cross section chips increased (which is not enough), while requiring higher tool life than at point $\mathrm{A}$.

In point 4 , cross section chips is fully utilized while the tool life to be exceeded, which means he will have to use the tool more stability.

In the point 5 are not fully utilized cross-section chips or tool life. Because of the smaller slope straight $P_{M 5}$ to the straight $P_{M}$, cross section chips is reduced compared to point $A$. Also, item point 5 requires a tool more persistence than stability at point $A$. So, at this point is not fully utilized cross-section of chips or tool life. In the points 4 and 5, the optimal speed $V_{i 4}$ and $V_{i 5}$ are higher than the optimal speed at point $A$. According to the relation (19), it follows that in these cases the optimal diameter $D_{i}$ increase assuming that the maximum diameter $D_{\max }$ and maximum speed $V_{\max }$ does not change. In the point 4 , the cross-section of chips has not changed in relation to point $A$ and there hasn't been increase to the main cutting resistance $F_{1 \max }$. Taking into account the relation (21), torque $M_{\max }$, at this point is increased in proportion to the increase of the diameter $D_{i}$. This increase of torque requires a check of transmission system machines, [2], [4], [5], [6], [7], [9], [15], [19], [21], [22].

\subsection{CLASSIC APPROACH TO EXERCISE REGIME IN THE CHARACTERISTIC POINT}

As it is said, the mode in point 4 corresponds to an increase in propulsive power movement along the line $P_{M}$ of constant cross-section chips to the intersection with the line $\bar{P}_{\text {max }}$. In point 4 , therefore, will only crosssection chips fully utilized compared to the initial state of the machine (point $A$ ), while the tool life to be exceeded. This means, that cross to the point 4 will have to pass the second line, depending on power and speed, which would correspond to the utilization of high persistence (line $P_{A 4}$ ). In adapting to the new requirements under this principle, it is necessary to use the tools of higher persistence, for example, shift from high-speed steel tools to carbide or ceramics tools. New optimal regime, which corresponds to point 4, requires a higher optimal speed of speed, $V_{i}>V_{i}$ . Since, the cross-section of chips remained constant, ie. at $g=$ const and $s_{\max }=$ const, this increase of speed $V_{i}$ can be achieved only by increasing $C_{v}^{\prime}$, the relation (4), ie using a tool higher persistence, if the relationship $g=a / s$ does not change.

By adopting a it $D_{\max }=$ const and $V_{\max }=$ const , Fig. 5, then the optimal diameter will be increased in point 4 , according to (20), ie.:

$$
D_{i 4}=D_{\text {max }} \cdot \frac{V_{i 4}}{V_{\text {max }}}=D_{\text {max }} \cdot \frac{\overline{V_{i}}}{V_{\text {max }}}=\overline{D_{i}}
$$

where $V_{i 4}=\overline{V_{i}}$, while: $\frac{\overline{V_{i}}}{D_{i}}=\frac{V_{\max }}{D_{\max }}$.

At a constant cross-section chips is $F_{1 \text { max }}=$ const, so the relation of powers in points 4 and A:

$$
\frac{\bar{P}_{\max }}{P_{\max }}=\frac{F_{1 \max } \cdot \bar{V}_{i}}{F_{1 \max } \cdot V_{i}}=\frac{\bar{V}_{i}}{V_{i}}
$$

The ratio of the optimal diameters, according to (19), is:

$$
\frac{\overline{D_{i}}}{D_{i}}=\frac{D_{\max } \cdot \frac{\overline{V_{i}}}{D_{\max }} \cdot \frac{\overline{V_{i}}}{V_{\text {max }}}}{V_{i}}
$$

as shown in the $V$ - $D$ diagram in Fig. 5. 
It is now (25) and (26) it follows that the increase in optimal diameter in proportion to the increase in the strength:

$$
\frac{\overline{D_{i}}}{D_{i}}=\frac{\bar{P}_{\text {max }}}{P_{\text {max }}}
$$

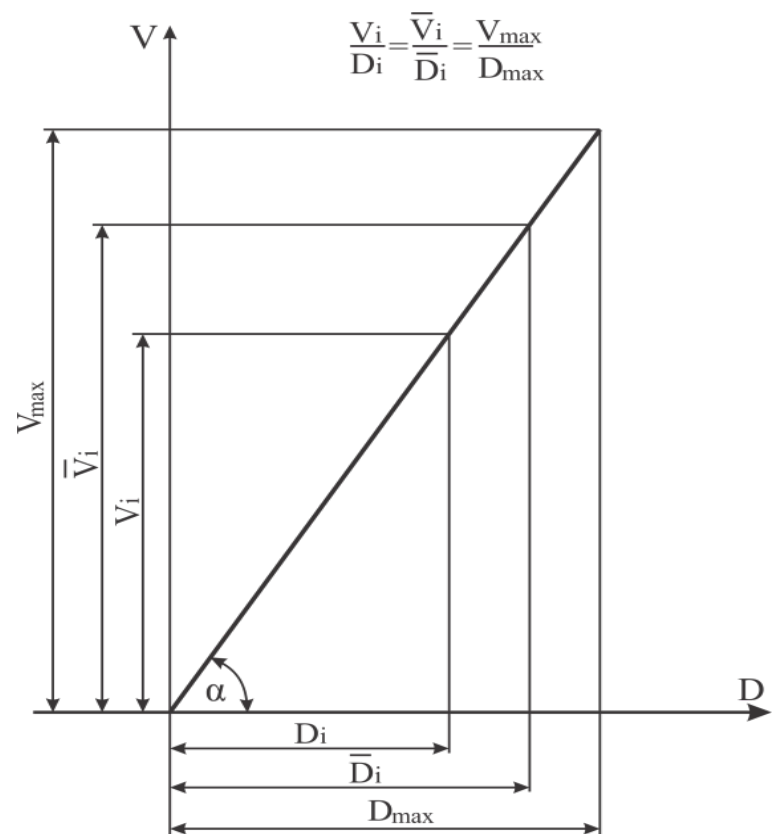

Fig. 5. Correlation between the optimal diameter $\left(D_{i}, \bar{D}_{i}\right)$

This increase $\bar{D}_{i}$ obviously must not exceed the value of the maximum diameter $D_{\max }$.

Torque $\bar{M}_{i}$ proportionally increases with the increase $D_{i}$, according to (21), follows the relation:

$$
\frac{\bar{M}_{\text {max }}}{M_{\text {max }}}=\frac{F_{1 \text { max }} \cdot \frac{\overline{D_{i}}}{2}}{F_{1 \text { max }} \cdot \frac{D_{i}}{2}}=\frac{\overline{D_{i}}}{D_{i}}
$$

Taking into account the (27) and (28), it follows that the torque is increased in proportion to the increase in power:

$$
\frac{\bar{M}_{\max }}{M_{\max }}=\frac{\bar{P}_{\max }}{P_{\max }}
$$

\subsection{A NEW APPROACH TO EXERCISE REGIME IN CHARACTERISTIC POINT}

The regime in point 4 , Fig. 6 , can be realized at constant torque $\bar{M}_{\text {max }}=M_{\text {max }}$, ie. in:

$$
\begin{aligned}
& \bar{F}_{1 \max } \cdot \frac{\bar{D}_{i}}{2}=F_{1 \max } \cdot \frac{D i}{2} \\
& \text { Since it is } F_{1 \max }=\overline{\bar{F}}_{1 \max }=\text { const, this }
\end{aligned}
$$

condition will be filled for $D_{i}=\bar{D}_{i}$, according to (20):

$$
D_{\text {max }} \cdot \frac{V_{i}}{V_{\text {max }}}=\bar{D}_{\text {max }} \cdot \frac{\bar{V}_{i}}{\bar{V}_{\text {max }}}
$$

The maximal diameter $D_{\max }$ is not changed, so, according to (30), it follows that:

$$
\frac{V_{i}}{V_{\text {max }}}=\frac{\bar{V}_{i}}{\overline{V_{\text {max }}}}
$$

The optimal speeds can be expressed through the rpm:

$$
\begin{aligned}
& V_{i} \cdot D_{i} \cdot \pi \cdot n_{i} \\
& V_{i} \cdot \overline{D_{i}} \cdot \pi \cdot \overline{n_{i}}
\end{aligned}
$$

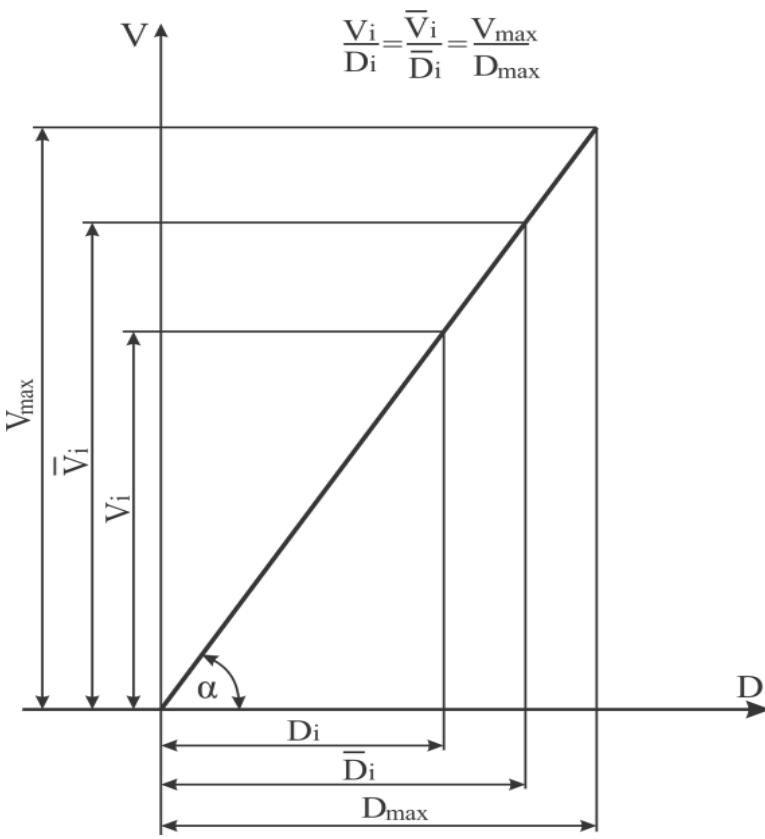

Fig. 6. Increasing the motive power at a constant crosssection of chips

We will prove, using operating diagram $(\mathrm{V}, \mathrm{D})$ Fig. 7, that in the case $\bar{V}_{i}=V_{\text {max }}$, the relations will be satisfied. In this, we will start from the working diagram in Fig. 7.

Real $n_{i}$ and $\overline{n_{i}}$ in the working diagram makes the angles $\alpha$ and $\beta$ with the abscissa, so from the corresponding triangles it follows that:

$$
\begin{aligned}
& \operatorname{tg} \alpha=\frac{V_{i}}{D_{i}}=\frac{V_{\text {max }}}{D_{\text {max }}} \\
& \operatorname{tg} \alpha=\frac{V_{i}}{D_{i}}=\frac{\bar{V}_{\text {max }}}{D_{\text {max }}}
\end{aligned}
$$




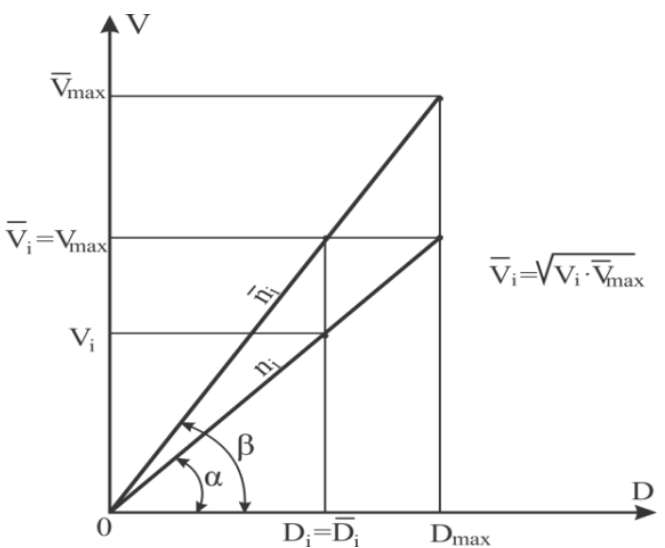

Fig. 7. Realization of a suitable regime for constant torque

Seeing as that $D_{i}=\bar{D}_{i}$, by dividing equation (33) will be:

$$
\frac{V_{\max }}{\bar{V}_{\max }}=\frac{V_{i}}{\bar{V}_{i}}
$$

which agrees with equation (31).

Taking into account that $V_{\max }=\bar{V}_{i}$, from (31) it follows that:

$$
\bar{V}_{i}=\sqrt{V_{i} \cdot V_{\max }}
$$

ie. the maximal speed for the new conditions will be:

$$
\bar{V}_{\max }=\frac{\bar{V}_{i}^{2}}{V_{i}}
$$

Based on the work table $(V, D)$ Fig. 7, where position of the lines of the optimal rpm $n_{i}$ and $\overline{n_{i}}$ are defined, in Fig. 8 gives the principal sawtooth diagram for the initial conditions and terms adapted to new needs. Lines of minimal and maximal rpm for the initial conditions are $n_{\min }$ and $n_{\max }$, and the new conditions $\bar{n}_{\text {min }}$ and $\bar{n}_{\text {max }}$. In this, obviously the lines $n_{i}$ and $\bar{n}_{\text {min }}$ are overlap.

Also, it is noted that the maximal rpm of the new conditions $\overline{\boldsymbol{n}}_{\max }$ was increased compared to the initial conditions $\left(n_{\max }\right)$. This increased high-speed machines, and thus also its productivity.

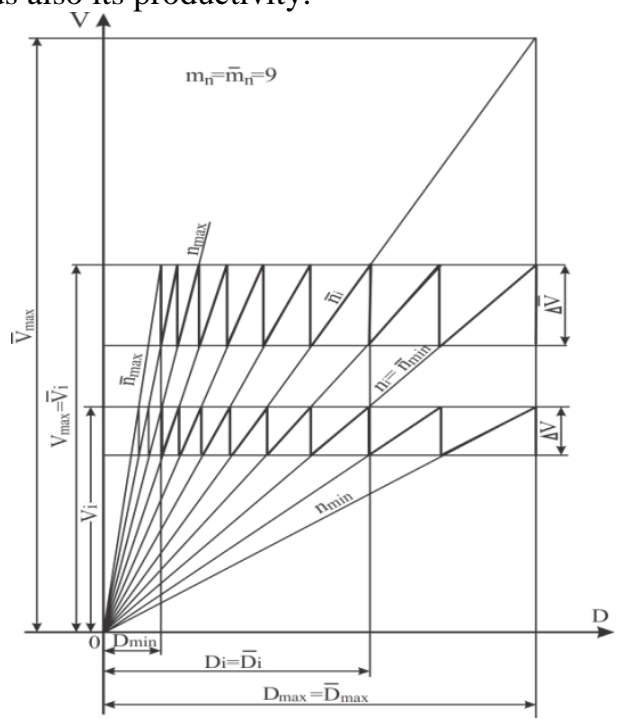

Fig. 8. The relation between the rpm for starting and new conditions

\section{THE CALCULATION EXAMPLE}

Parametars:

- Machine tool: universal lathe.

- The gear for the main movement: gear train transmission with removable group gears.

- Treatment type: coarse.

- Tools: Turning carbide quality the knife P25. Angle of attack $k=45^{\circ}$.

- $\quad$ Economical tool life: $T=90 \mathrm{~min}$.

- A key workpiece material: alloyed structural steel (CrNi): $R_{m}=75\left[\mathrm{kN} / \mathrm{cm}^{2}\right]$

- $\quad$ Maximal step: $s_{\max }=1,4[\mathrm{~mm} / \mathrm{o}]$

This step is obtained based on the corresponding standard calculations corresponding to a maximal roughness $\quad R_{\max }=160[\mu \mathrm{m}]$ and the radius of curvature tip of knife $r=1,5[\mathrm{~mm}]$

- $\quad$ The efficiency of machines $\eta=0,85$

- Maximal diameter of the adopted machine: $D_{\text {max }}=650[\mathrm{~mm}]$

- Coefficients of of frailty chips to tool and workpiece material $g=8$.

- Constants and exponents workability (for $T_{t}=60 \mathrm{~min}$ :

$$
\begin{array}{lcc}
C_{V}=0,1324 & {\left[\frac{m}{s} \cdot m^{2}\right]} & \\
x=0,15 & y=0,45 & m=0,2 \\
\zeta_{k}=1 & \zeta_{p}=1 & Z=2 \\
C_{k}=4,356 \cdot 10^{8}\left[\frac{N}{m^{2}}\right] & \\
x_{1}=1 & y_{1}=0,78 &
\end{array}
$$

- $\quad$ Constant workability for cutting speed according to (4) and (5) will be:

$C_{V}^{\prime}=\frac{C_{V} \cdot \zeta_{k} \cdot \zeta_{p}}{T^{m}} \cdot \sqrt{\frac{T_{t}}{T}}=\frac{0,1324 \cdot 1 \cdot 1}{(90 \cdot 60)^{0,2}} \cdot \sqrt{\frac{60 \cdot 60}{90 \cdot 60}}=0,01938\left[\frac{\mathrm{m}}{\mathrm{s}} \cdot \mathrm{m}^{2}\right]$

- Maximum driving power machine according to (18) will be:

$$
\begin{gathered}
P_{\max }=\frac{C_{k} \cdot C_{V}^{\prime}}{\eta} \cdot g_{\max }^{x_{1}-x} \cdot s_{\max } \\
P_{\max }=\frac{4,356 \cdot 10^{8} \cdot 0,01938}{0,85} \cdot 8^{1-0,15} \cdot 0,0014^{1+0,78-0,15-0,45}=24950
\end{gathered}
$$

Sustained $P_{\max }=25[\mathrm{~kW}]$.

- $\quad$ The optimal speed of cutting according to (17) will be: 


$$
\begin{aligned}
V_{i} & =\frac{C_{V}^{\prime}}{g_{\max }^{x} \cdot s_{\max }^{x+y}}=\frac{0,01938}{8^{0,15} \cdot 0,0014^{0,15+0,45}} \\
V_{i} & =0,7317\left[\frac{m}{s}\right]=43,9\left[\frac{m}{\min }\right]
\end{aligned}
$$

- $\quad$ Cutting depth in the optimal point is:

$a_{\text {max }}=g_{\text {max }} \cdot s_{\text {max }}=8 \cdot 1,4=11,2[\mathrm{~mm}]$

- $\quad$ The optimal diameter (steel workpiece material), [5], [6]:

$$
D_{i}=0,74 \cdot D_{\max }=0,74 \cdot 650 \approx 480[\mathrm{~mm}]
$$

- Maximal optimal speed according to (21) and (35) are:

$$
\begin{aligned}
& V_{\max }=\frac{D_{\max }}{D_{i}} \cdot V_{i}=\frac{650}{480} \cdot 0,7317=0,9908\left[\frac{\mathrm{m}}{\mathrm{s}}\right]=59,45\left[\frac{\mathrm{m}}{\min }\right] \\
& V_{\text {max }}=\bar{V}_{i} \\
& \bar{V}_{\max }=V_{\max } \cdot \frac{\bar{V}_{i}}{V_{i}}=0,9908 \cdot \frac{0,9908}{0,7317}=1,34165\left[\frac{\mathrm{m}}{\mathrm{s}}\right]=80,5\left[\frac{\mathrm{m}}{\mathrm{min}}\right]
\end{aligned}
$$

- Maximal resistance to cutting according to (1) and (6) is:

$F_{1 \max }=C_{k} \cdot g^{x^{1}} \cdot s_{\max }^{x_{1}+y_{1}}=4,356 \cdot 10^{8} \cdot 8^{1} \cdot 0,0014^{1+0,78}=28992,5[\mathrm{Nm}]$

Control results can be derived from the relation $P_{\text {max }}=\frac{F_{1 \max } \cdot V_{i}}{\eta}$.

- $\quad$ Optimal maximum torque is:

$M_{\max i}=F_{1 \max } \cdot \frac{D_{i}}{2}=28992,5 \cdot \frac{0,48}{2}=6958,2[\mathrm{Nm}]$

- Maximum torque according to (23) is:

$M_{\max }=F_{1 \max } \cdot \frac{D_{\max }}{2}=28992,5 \cdot \frac{0,65}{2}=9422,6[\mathrm{Nm}]>M_{\operatorname{maxi}}$

- Power, considering the utilization of tools according to (12), is:

$P_{A}=\frac{C_{k}}{\eta} \cdot C_{V}^{\prime \frac{x_{1}+y_{1}}{x+y}} \cdot g^{x_{1}-x \cdot \frac{x_{1}+y_{1}}{x+y}} \cdot V^{1-\frac{x_{1}+y_{1}}{x+y}}$

$P_{A}=\frac{4,356 \cdot 10^{8}}{0,85} \cdot 0,01938^{\frac{1+0,78}{0,15+0,45}} \cdot 8^{1-015 \cdot \frac{1+0,78}{0,15+0,45}} \cdot V^{1-\frac{1+0,78}{0,15+0,45}}$

$P_{A}=\frac{13488,46}{V^{1,9667}}[W]$

- Power, considering the utilization of machine according to (15) will be:

$$
\begin{gathered}
P_{M}=\frac{C_{k}}{\eta} \cdot g^{x_{1}} \cdot S_{\max }^{x_{1}+y_{1}} \cdot V \\
P_{M}=\frac{4,356 \cdot 10^{8}}{0,85} \cdot 8^{1} \cdot 0,0014^{1+0,78} \cdot V \\
P_{M}=34108,0 \cdot V[W]
\end{gathered}
$$

- $\quad$ The maximum power in the new optimal point, according to (24), is:

$$
\bar{P}_{\max }=P_{\text {max }} \cdot \frac{\bar{V}_{i}}{V_{i}}=24950 \cdot \frac{0,9908}{0,7317}=33785[\mathrm{~W}]
$$

In this relation must be satisfied relation:

$$
\bar{P}_{\max }=\frac{F_{1 \max } \cdot \bar{V}_{i}}{\eta}
$$

- $\quad$ Relation of power and cutting speed in a new and starting optimal point is:

$$
\frac{\bar{P}_{\text {max }}}{P_{\max }}=\frac{\bar{V}_{i}}{V_{i}}=1,354
$$

- $\quad$ Tool life at speed $\bar{V}_{i}=V_{\text {max }}$ determined on the basis of constant workability to (4):

$\overline{C_{V}^{\prime}}=\bar{V}_{i} \cdot g^{x} \cdot s^{x+y}=0,9908 \cdot 8^{0,15} \cdot 0,0014^{0,15+0,45}=0,02625\left[\frac{\mathrm{m}}{\mathrm{s}} \cdot \mathrm{m}^{2}\right]$

$$
\begin{aligned}
& C_{V}^{\prime}=\frac{C_{V} \cdot \zeta_{k} \cdot \zeta_{p}}{T^{m}} \cdot \sqrt[z]{\frac{T_{t}}{T}} \\
& 0,02625=\frac{0,1324 \cdot 1 \cdot 1}{\bar{T}^{0,2}} \cdot \sqrt{\frac{6 O \cdot 60}{\bar{T}}}
\end{aligned}
$$

It follows that:

$$
\bar{T}=3499[\mathrm{~s}]=58,3[\mathrm{~min}]<T i_{i}=90[\mathrm{~min}]
$$

Obviously, the existing tool $\left(T=T_{i}=90 \mathrm{~min}\right)$, will be at an increased speed $\bar{V}_{i}$, reduced stability $\bar{T}$.

- Tool selection increased stability

Constants workability of the new requirements is:

$$
\overline{C_{V}^{\prime}}=\frac{C_{V}}{\bar{T}^{\bar{m}}} \cdot \sqrt{\frac{60 \cdot 60}{\bar{T}}}
$$

- Optimal speed for starting and new state will be:

$$
\begin{aligned}
V_{i} & =\frac{C_{V}^{\prime}}{g_{i}^{x} \cdot s_{i}^{x+y}} \\
\bar{V}_{i} & =\frac{\overline{C_{V}^{\prime}}}{g_{i}^{x} \cdot s_{i}^{x+y}}
\end{aligned}
$$

Dividing these relations follow relation of speeds:

$$
\frac{\bar{V}_{i}}{V_{i}}=\frac{\overline{C_{V}^{\prime}}}{C_{V}^{\prime}}=\frac{0,9908}{0,7317}=1,354
$$

is:

Constant workability that matches the new state

$$
\overline{C_{V}^{\prime}}=1,354 \cdot C_{V}^{\prime}=1,354 \cdot 0,01938=0,02625\left[\frac{m}{s} \cdot m^{2}\right]
$$

which is consistent with the result obtained by relation (50).

Using an iterative process, the assumed values, constants and exponents of machinability, for tool carbide, will be:

$$
\bar{m}=0,25 \quad \overline{C_{V}}=0,28
$$

Considering the relation (52) it follows that,

$$
0,02625=\frac{0,28}{\bar{T}^{0,25}} \cdot \sqrt{\frac{60 \cdot 60}{\bar{T}}}
$$

It follows that the stability of the adopted new tool will be:

$$
\begin{aligned}
& \bar{T}^{0,75}=640,244 \\
& \bar{T}=5518 \mathrm{~s}=91,97[\mathrm{~min}]
\end{aligned}
$$


which does not deviate much from the initial tool $(T=90$ $\min )$.

It should be noted that at this may adopt another kind of tool material and its other quality.

- $\quad$ The optimal speed for starting the new conditions will be:

$$
\begin{aligned}
& n_{i}=\frac{V_{i}}{D_{i} \cdot \pi}=\frac{0,7317}{0,48 \cdot \pi}=0,485 \mathrm{o} / \mathrm{s}=29,1[\mathrm{o} / \mathrm{min}] \\
& \bar{n}_{i}=\frac{\bar{V}_{i}}{D_{i} \cdot \pi}=\frac{0,9908}{0,48 \cdot \pi}=0,657 \mathrm{o} / \mathrm{s}=39,4[\mathrm{o} / \mathrm{min}]
\end{aligned}
$$

Geometric factor changes, given the rpm for starting and new state will be:

$$
\begin{gathered}
\varphi=\frac{n_{2}}{n_{1}}=\frac{n_{3}}{n_{2}}=\frac{n_{4}}{n_{3}}=\ldots \\
\bar{\varphi}=\frac{\bar{n}_{2}}{\bar{n}_{1}}=\frac{\bar{n}_{3}}{\bar{n}_{2}}=\frac{\bar{n}_{4}}{\bar{n}_{3}}
\end{gathered}
$$

If you draw a principled sawtooth (working) diagram (Fig.8) for starting and new situation, it can be concluded that the factors of geometric changes and degrees of gear for both states are equal, ie.:

$$
\begin{aligned}
\varphi & =\bar{\varphi} \\
m_{n} & =\bar{m}_{n}
\end{aligned}
$$

Also, he notes that the optimal rpm initial condition $n_{i}$ equal to the minimum rpm of the new state, ie.:

$$
n_{i}=\bar{n}_{\min }
$$

while the relation of optimal rpms apply:

$$
\frac{\bar{n}_{i}}{n_{i}}=\varphi^{k}
$$

where $k$ is a constant integer that is readily determined according to the diagram in Fig. 8.

It should be noted that in the new conditions, each workpiece diameter $D$, treated at higher rpms (higher speed) in relation to rpm in the initial state.

\section{- Determination of productivity}

The relation of capital time for a new and initial state $(l=$ const $)$, for the optimal point will be,

$$
\frac{\bar{t}_{g i}}{t_{g i}}=\frac{\overline{\bar{n}_{i} \cdot \bar{s}}}{\frac{\ell}{n_{i} \cdot s_{i}}}=\frac{n_{i} \cdot s_{i}}{\bar{n}_{i} \cdot s_{i}}=\frac{n_{i}}{\bar{n}_{i}}
$$

Considering that $\bar{n}_{i}>n_{i}$ it follows that $\overline{t_{g i}}<t_{g i}$

It follows that the relation productivity, taking into account the relation (61):

$$
\frac{\bar{Q}_{i}}{Q_{i}}=\frac{\bar{n}_{i}}{n_{i}}=\frac{t_{g}}{t_{g}}=\text { const }
$$

\section{CONCLUSION}

Increasing the exploitation characteristics of the universal lathe, so that they adapt to the new needs and lead to a higher technological level, rational to perform adopting variants when the optimal point moves in the direction of full utilization section filings.
As shown, increasing the driving power of the universal lathe while simultaneously increasing the rpm of the main spindle, allows achieve a new optimal regime. At this, the optimal diameter remained unchanged until the torque, resistance of the auxiliary and the main movement, not increased. With this, reconstruction costs are minimal and the accuracy of the machine is not compromised. When this is achieved by improving the machines characteristics as the the smallest needs for its reconstruction, considering that avoided checking the stability of the transmission system and stiffness of the supporting structure of the machinery ie tools. In this case, it is necessary to increase the cutting speed in a precisely defined relative to is analytically determined, with the use of tools greater stability. Also, there is no need to change the kinematics of the system. It is only necessary to make the correction rpm at the entrance to gear, for example, via a belt gear.

The new optimal mode, as shown, allows increase productivity in all areas of processing range in diameter workpiece.

The presented methodology can be relatively easily generalized to other treatment processes, ie machine tools (such as drills and milling machines), taking into account that each treatment has its own specificity in terms of behavioral function workability.

The present work can serve designers to practice as a theoretical model in solving the problems of modernization of the existing machine tool and can represent a first approximation, considering that they did not take into account any effects.

\section{REFERENCES}

[1] Zahar, S.: Machine tools 1, Yugoslav Society for Tribology, Kragujevac, 1933.

[2] Cernov, N.N.: Metalorežnjušie stanki, Mašinostroenie, Moskva, 1988.

[3] Tormazimanov, G.A.: Prekrovanie metaloreznjuših stanki, Mašinostroenie, Moscow, 1990.

[4] Muren, H.: Construction tools machinery, Faculty of Engineering, Ljubljana, 1983.

[5] Stankovic, P.: Machine tools 1 and 2, Building Book, Belgrade, 1978.

[6] Milacic, V.: Machine tools 1 and 2, Faculty of mechanical engineering, Belgrade, 1980.

[7] Vragov, J.D.: Analiz komponovok metalorežnjuške stanki, Mašinostroenie, Moscow, 1989.

[8] Acerkan, N.S. i dr.: Metalorežušie stanki 1 and 2, Mašinostroenie, Moscow, 1975.

[9] Hans, K.B.: NC Hanabuch, NC-gesellschäft, Bad König, 1977.

[10] Opitz, H.: Moderne produktionstechnik, N. Girardet, Essen, 1981.

[11] Trent, E. M.: Metal Cufting, Buterworths, London, 1985.

[12] Gatalo, R. Zeljkovic, M.: Calculation of the main characteristics of machine tools for machining, FTS, Novi Sad, 1998.

[13] Milikic, D.: Technology machining, FTS, Novi Sad, 2003.

[14] Kalajdzic, M.: Technology machining, manual, Faculty of mechanical engineering, Belgrade, 1999. 
[15] Weber, H.: Grundlagen des Spanes, Veb-VerlagTechnik, Berlin, 1986,

[16] Bruins D.H.: Werzeuge und Werkzeugemaschinet, Carl Hanser Verlag, Munchen, 1996.

[17] Kučeo, I. M.: Metalorežušćie stanki, Vsnovi konstruinovania i rasčeba, Mašinostroenie, Leningrad, 1980.

[18] Dunaev, P.F.: Konstruirovanie uzlov i detalej mašin, V. Š., Moskva, 1986.

[19] Tochtermann W.: Konstruktioselemente des maschinen banes, Springer-Verlag, Berlin 1998.
[20] Tobias, S.A.: Machine Tool, Bleckie, Glasgow, 1995.

[21] Balakschin B.S.: Technologie des Werzengmaschinennaus, Veb Verlog Technik, Berlin, 1983.

[22] Puš, V. E.: Konstruirovanie metallorežišnih stankov, Mašinostroenie, Moskva, 1983.

[23] Pejovic B., Tolic A., Todic T., Ljamic D.: One way to improve the exploitation characteristics of the universal drills with the lowest needs for reconstruction, Journal TECHNIQUE, br. 1, Mechanical Engineering 58, Belgrade 2009. 